\title{
Central hepatectomy: A valuable option to avoid posthepatectomy liver insufficiency in patients requiring extensive liver resection
}

\author{
Mehmet Fatih Can, Murat Urkan, Emin Lapsekili, Rahman Șenocak, Ümit Alakuș
}

Cite this paper as:

Can MF, Urkan M, Lapsekili

E, Şenocak R, Alakuş Ü.

Central hepatectomy: A

valuable option to avoid posthepatectomy liver insufficiency in patients requiring extensive liver resection. Turk J Surg 2017; 33: 292-293.

Department of General Surgery, Health Sciences University Gülhane School of Medicine, Ankara, Turkey

This study was presented at the $13^{\text {rd }}$ Turkish Congress of Hepatopancreatobiliary Surgery, 1-4 November 2017, Antalya, Turkey.

Address for Correspondence Mehmet Fatih Can e-mail:mfcanmd@gmail.com

Received: 13.09.2017 Accepted: 01.11.2017

CCopyright 2017 by Turkish Surgical Association www.turkjsurg.co
Despite being uncommon, posthepatectomy liver failure (PLF) is a dreadful complication following extended hepatectomy or liver trisectionectomy. It has been reported that liver insufficiency may occur in as high as $12 \%$ of posthepatectomy patients, especially in those who have a concomitant chronic liver disease, hepatosteatosis or history of receiving long-course ( $>6$ cycles) chemotherapy (1). Central hepatectomy or mesohepatectomy, defined as en-bloc anatomical resection of liver segments 4-5 and 8 , is a valuable option in patients with central large or multiple liver lesions to minimize PLF caused by the loss of a considerable portion of functional liver parenchyma following extensive resections (2). The purpose of this video-based article is to share key procedural components to be adhered to when performing central hepatectomy.

In order to render a final video reflecting our technique of central hepatectomy, we reviewed raw operation videos recorded in our surgical video collection. Every important step of the procedure was assessed visually to determine if it had been performed the same way in each case. The step was considered an integral part of our approach and reproducible if it had taken place in the majority of operations. The final video is composed of video clips demonstrating those standardized certain steps. Informed consent was obtained from all patients.

All extended anatomical hepatic resections in our department are performed through a shortened modified Makuuchi incision. The right and left triangular ligaments are divided. The right and left hepatic veins are partly exposed, but not encircled with umbilical tape. Following preparation for the Pringle maneuver, parenchymal transection starts without preceding hilar dissection. The Pringle maneuver is applied intermittently (15 min occlusion and $5 \mathrm{~min}$ release) during transection. Parenchyme splitting is initiated just right to the falciform ligament between the left lateral (liver segments 2-3) and left medial (liver segment 4) sections, during which inflow structures of liver segment 4 arising off of the hilar plate are ligated and divided (Video). The transection on this plane is continued down to the vena cava - middle hepatic vein junction. The middle hepatic vein is secured by passing a tape around it (Video). Thereafter the attention is turned to the hilar and cystic plates again. The cystic duct is ligated and transected, and the Callot triangle is exposed. This allows for the surgeon to utilize intraparenchymal Glissonian approach when exposing the right anterior sector plate structures. The whole plate of the right anterior section is exposed en-bloc and divided by using a linear stapler (Video). This step is followed by parenchymal transection between the right anterior and posterior sections. During this transection, the split line is on the left-side of the right hepatic vein and proceeds cephalad. The resection is completed after ligation and division of the middle hepatic vein (Figure 1). It is our practice to utilize the White test to check for bile leaks at the end of the procedure. In our series, postoperative bile leak occurred in 20 percent of patients, of whom one required endoscopic stent placement. No other significant morbidities, including PLF, were detected postoperatively. The median length of hospital stay was 7 (5-13) days.

In summary, central hepatectomy or mesohepatectomy, which relies on preservation of at least one more liver segment as compared to anatomical trisectionectomy, is a good alternative for curative treatment of patients who have large or multiple liver masses with median bi-sectoral involvement. With the last ten consecutive patients having been operated on using this technique, our approach seems safe, feasible and reproducible, resulting in low morbidity rates without occurrence of posthepatectomy liver failure. 

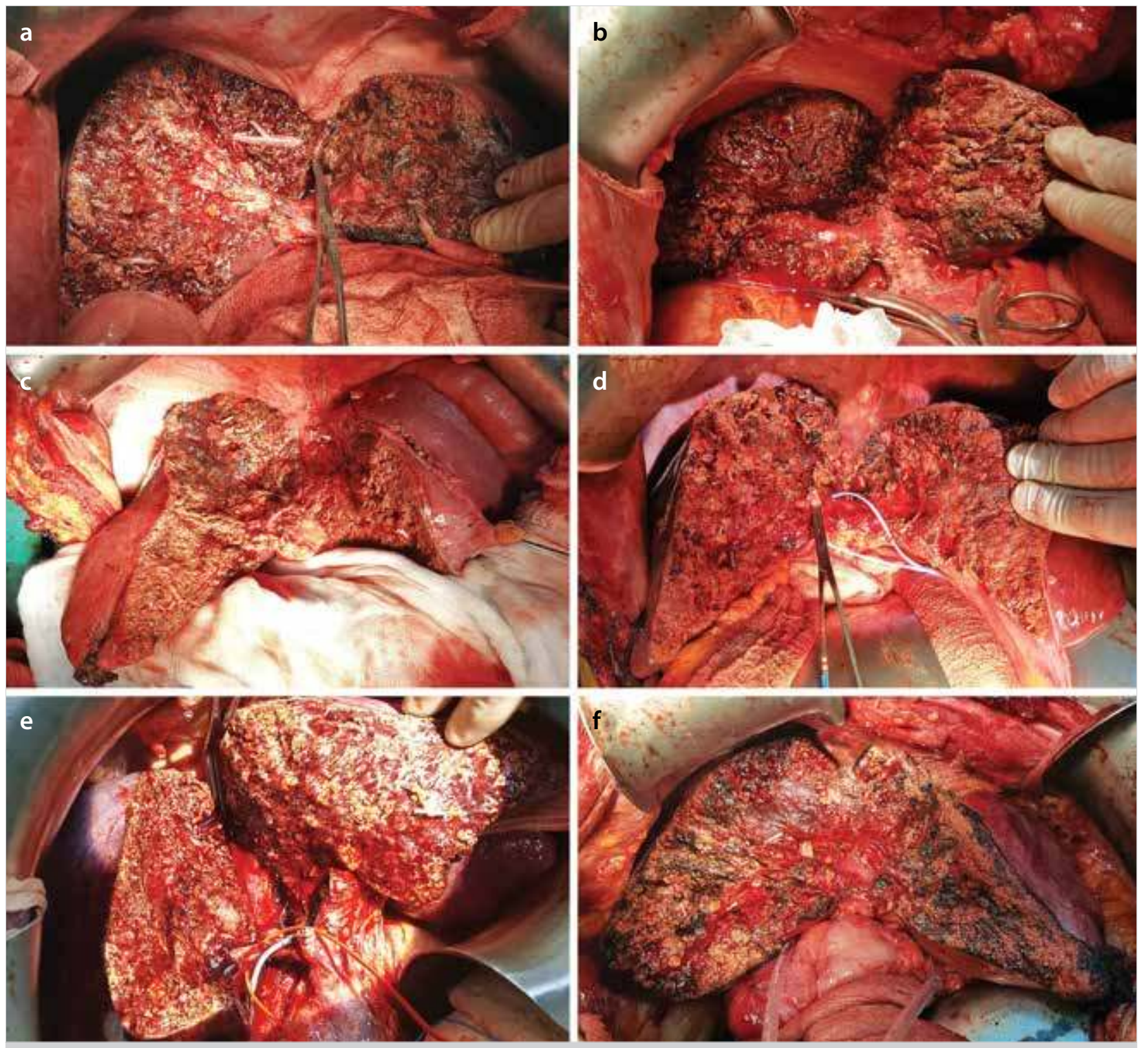

Figure 1. a-f. Views of surgical field (a-f) obtained immediately after the resection has been completed by means of the technique described herein

Informed Consent: Written informed consent was obtained from patient who participated in this study.

Peer-review: Externally peer-reviewed.

Author Contributions: Concept - M.F.C.; Design - M.U.; Supervision M.F.C., R.Ş.; Resource - E.L., Ü.A.; Materials - M.U.; Data Collection and/or Processing - Ü.A.; Analysis and/or Interpretation - R.Ş., M.F.C.; Literature Search - M.F.C.; Writing Manuscript - M.U., R.Ş.; Critical Reviews - Ü.A., E.L.

Conflict of Interest: No conflict of interest was declared by the authors.

Financial Disclosure: The authors declared that this study has received no financial support.
Video: Central hepatectomy - surgical technique

\section{REFERENCES}

1. Skrzypczyk C, Truant S, Duhamel A, Langlois C, Boleslawski E, Koriche $D$, et al. Relevance of the ISGLS definition of posthepatectomy liver failure in early prediction of poor outcome after liver resection: study on 680 hepatectomies. Ann Surg 2014; 260: 865870. [CrossRef]

2. Lee SY, Sadot E, Chou JF, Gönen M, Kingham TP, Allen PJ, et al. Central hepatectomy versus extended hepatectomy for liver malignancy: a matched cohort comparison. HPB (Oxford) 2015; 17:10251032. [CrossRef] 